\title{
FUNDAMENTALS OF METHODOLOGY FOR CANCER CAUSES STUDIES
}

\section{Raikhman J. G.}

\section{Center for Cancer Prevention, Ashdod, Israel}

Lack of consistency of cancer epidemiology methods with human life conditions often lead to wrong conclusions concerning cancer causes and to ineffective cancer preventing measures. In the article, the new methodological approach in suggested to study cancer causes based on author's concept of the carcinogenic situation as a continuously developing multilevel system. The methodology for the system research of the carcinogenic situation created a new possibility for detecting existing specifics in cancer morbidity under multifactor combination of environmental conditions and human life style. A study of the carcinogenic situation is conducted on the basis of static and dynamic models. Dynamic models are the basis for cancer morbidity forecast. The new methodology for the system research and carcinogenic situation management brings in new perspectives in cancer prevention problem solution measures.

Key words: cancer epidemiology, carcinogenic situation, methodology for system research

\section{Introduction}

Modern concepts in cancer causes research were developed based on epidemiological and experimental studies results. There is a direct link between these results and research methods applied. Inadequate methods applied may bring in wrong conclusions. These, in turn, may result in wrong and ineffective cancer preventing actions.

Methods used until now in epidemiological studies mostly rely on experimental oncology. At the same time, the research purposes of experimental oncology and cancer epidemiology are noticeably different.

Experimental carcinogenesis looks into carcinogenic potential of various natural and anthropogenic agents, while cancer epidemiology investigates specifics in cancer development and causes of cancer [ $1-5]$.

In a lifetime, human body is affected by numerous environmental and life style carcinogenic and modifying factors which determine specifics and differences in cancer development.

Experimental studies examine carcinogenic properties of a specific agent. To achieve the goal, the respective methodology is limited to «the dose-response» method.

Several experimental oncology researchers recognized that animal experimentation results must be confirmed by human epidemiological studies [6]. However, for a long time, epidemiological researches were guided by an idea that cancer causes should be searched for in the effect of specific carcinogenic agents. Moreover, for these researches, the experimental oncology methods were used which did not allow to evaluate an impact of multiple complex of environmental and life style factors.
After the increased cancer rates were revealed in industries processing minerals that in experimental studies showed their carcinogenic properties, researches in the area of so called occupational cancer were actively promoted [5].

Previously, the epidemiological occupational cancer studies were conducted using the «case-control» method. According to this method, number of patients with specific cancer belonging to an experimental group (occupational group, i.e. people contacting with specific cancer agent) was compared with the number of similar cancer patients in control group (i.e. those without occupational history of contact with this specific carcinogenic agent).

Occupational cancer studies encountered difficulties when interpreting study results. These difficulties resulted from various life styles that influenced carcinogenesis process in man (smoking, drinking alcohol etc.).

The above mentioned cofactors greatly influence the occupational cancer rate. Lack of objective evaluation of carcinogenic effect caused by so called «additional» or «third» factors on occupational groups became serious problem for interpretation of cancer risk under various working conditions. Main drawback of such studies was that an effect of the above mentioned «additional» factors was studied neither in experimental group nor in control group. Consequently, the results of comparative examination of these groups became questionable.

As a result, to the solution of this problem another methodological approach was needed.

Numerous carcinogenic and modifying carcinogenesis factors created a complicated methodological issue for researchers.

It was essential to address the issue of cancer causes detection under combined effect of complex combination 
of environmental and human life style factors. However for a long time yet, methods used to solve this problem did not meet the research needs. Actually by the early 90 s of the last century, a paired comparison method to compare experimental and control groups was mostly used which did not match the current situation in people's regular life. This method was not able to address the multifactor complex issue in scientific research.

Several oncologists-epidemiologists believed that the main analytic base for cancer epidemiology research was the comparison of patients having specific malignant tumors (experimental group) with population groups these patients belonged to [3, 7].

Actually, it was the same «case-control» method widely used in occupational cancer research. This method suggested two comparison approaches:

1) comparison of studied factors occurrence in cancer patients and healthy individuals ( «general picture» of cancer patient);

2 ) comparison of cancer morbidity in the population group exposed to studied factors with the nonexposed group (cohort study).

The first approach was aimed at selecting an informative set of indicators characterizing two states: sick or healthy. This allows to distinguish personal habits and life styles of sick and healthy individuals.

This comparison approach does not permit to address the issue concerning the influence of numerous environmental factors on malignant tumors morbidity because sick people are examined without taking into account the combination of their life conditions and are compared with the control group which is also socially heterogeneous.

This approach does not allow to determine causes of differences in cancer morbidity in various geographical areas either. It can not be the base for analytical studies in cancer epidemiology because «the epidemiology observation unit is not an individual person but a group, a community, a population» [8].

An individual always manifests and realizes oneself through complicated multidimensional system of social relations. Consequently, in this respect, none of so called personal habits and special features are strictly individual. These, with specific occurrence, are repeated in various populations and are reflecting common for all or specific for selected population characteristics of their life style.

The second comparison approach which is based on examination of populations is called the cohort method. Formally, this approach corresponds better with principles of epidemiological research, but has considerable methodological drawbacks.
The problem is that under natural life conditions, it is virtually impossible to isolate groups of people exposed or non-exposed to a certain factor. As a rule, a researcher has to work with groups of people exposed to numerous factors of different intensity and in different combinations.

\section{Study results and their discussion}

The next historic stage in cancer epidemiology research was the development of carcinogenic situation concept and methodology for system analysis of this situation suggested and described in details by Rakhman J. G. in several monographs and articles [9-13].

According to author's concept, cancer morbidity is a final result of carcinogenic situation development, a quantitative characteristic at certain time stage of this development.

A total carcinogenic situation may be pictured as a multilevel hierarchically built system with centered human population interacting with natural and socialeconomic environmental factors. The relationships within human population are presented at the first (highest) level of this system. The relationships between human body and specific physical and chemical parameters of natural ecosystems (soil, water, climate, atmosphere), and also components featuring various anthropogenic sources of carcinogenic and carcinogenesis modifying environmental factors (industrial and domestic) are included in the second level. The relationships between various organs/tissues of human body (as components of certain functional system) and carcinogens and also carcinogenesis modifying factors (both natural and anthropogenic) are presented at the third level.

Such system structure reflects dialectical unity of human being's biological nature and social identity.

One of the main methodological principles of the system research is the analysis/synthesis unity. The system research never involves analytical study of a selected object without precise identification of this object within the large system. Building a certain variety of simulation models each describing the effect of one or another interaction on object's behavior is one of the main tasks of research focused on system object.

After the needed simulation models have been built and studied, the following task is to unite their various performance ways into one integral picture of the carcinogenic situation. 
For such integration, the regression analysis method represents an effective tool which can be used to quantitatively assess the comparative effect of single factors or sets of factors on cancer morbidity (i.e. factors priority ranking). Knowing the factor's priority rank concerning the morbidity is crucial for potentially expected medical and economic effectiveness of cancer prevention measures.

The integrity of any system becomes most evident when system changes are being monitored during certain period of time: when changes in one of its subsystems inevitably bring in changes in other subsystems and, first of all, in system generating factor. This is fully applicable to such system as the carcinogenic situation. The examination of dynamics of carcinogenic situation system must be based on information about this system's structural and functional properties and features. When considering the set of environmental factors as an integral part of the carcinogenic situation, one should take into account that each single component of the system develops with its own specific development rate according to its nature or under impact of other interacting system components.

Due to ever changing social and economic conditions of people's life, cancer morbidity which is a function of carcinogenic situation can not be stable. Due to environmental processes, cancer morbidity is changing because it is a delayed effect of system's functioning. Cancer morbidity changes occur not immediately, but after certain, sometimes very long period of time.

The development of the carcinogenic situation during certain period of time depends on the situation's initial state. Different initial parameters bring in different results. Consequently, the first stage to study the carcinogenic situation must be the comparative examination of spatial varieties of malignant tumors morbidity in connection with the combination of environmental factors based on data for certain initial period of time.

At this stage, not only the causes of morbidity spatial varieties are determined, but also the effect size (effect priority ranking) for any environmental factors on cancer morbidity. Initial time data recorded for all spatial observation units serve as a starting point for further examination of system's dynamics.

The main point of the second study stage is the transfer from static to dynamic model where certain elements reflect characteristics at consequent time periods. At this stage, time changes in factor indicators and cancer morbidity are examined by comparing certain spatial data. This second stage allows to detect not only the link between time changes in cancer morbidity and parameters of environmental components, but also to identify the manifestation moment for such changes, and ipso facto, to determine hidden, latent period of cancer development within the population. Using these data, it is possible to develop the morbidity forecast.

According to observation data [10], the spatial bases for study of dynamics of carcinogenic situation system and forecast of cancer morbidity should be the division of geographical territory based on soil/climate characteristics but not on administrative principle.

In several administrative territories, soil/climate conditions are far from being uniform, and are distributed non-uniformly. Therefore, average data for separate administrative territories may not allow to detect development trends determined by interaction between natural and social-economic conditions of people's life. These trends are manifested in cancer morbidity rate.

Multifactor models studies do not permit to take into account all interconnected factors. Thus usually, the most essential factors are selected according to their priority ranking.

An important feature of carcinogenic situation as a system is that the final result of its development (cancer morbidity) is the delayed effect. A delay of cancer effect due to various factor characteristics occurs unevenly, and is linked with specific features of each of them. Different components of carcinogenic situation are developing unevenly which makes it very difficult to conduct time comparison and evaluation of combined effect due to exposure to environmental factors on morbidity changes.

In mathematical statistics, the direction and duration of delay of one interconnected series from other is determined by time lag. When comparing the dynamics series, first of all, the time lag is to be estimated (by calculating their intercorrelation). The time lag extent and direction are determined based on the highest correlation coefficient. The highest correlation coefficient for two interconnected series is obtained when one series is shifted from another to one lag period.

The author used the time lag characteristics as criteria for assessing a latent period of environmental factors effect on cancer morbidity and for predicting the morbidity rate for certain time period.

The methods described above are showing the direct way to study the dynamics of carcinogenic situation and, based on this study, to forecast cancer morbidity. In order to apply the method, it is necessary to build the dynamics series which characterize time changes in parameters of factor features concerned. These dynamics series 
should cover the time period not less than 15 -20 years. In this case it is considered, that the sound forecast can be developed for up-coming 5 - 10 years.

Environmental changes which took place at the time of the science and technology revolution, and changes in social-economic and living conditions influenced the life style of population as a whole. However, this impact on various generations of living population (age groups) was not similar. Thus, analysis of cancer morbidity rate dynamics for age groups is of great importance. This rate reflects environmental exposure specifics for various generations of living population.

Changes in dynamics for age groups not only characterize the morbidity rate for various population groups for a certain period of time, but also reflect the effects of exposure to various states of the environment which were developed in different times of people's life. Some of these states of the environment existed only in the past, so they did not impact young populations, while other affected more young people without influencing older generations.

A study of the link between cancer morbidity among selected age population groups and environmental changes (indirect research method to study the dynamics of the carcinogenic situation system) permits to obtain important information about space and time trends of system development.

\section{Conclusions}

To summarize, a study of such complex dynamic system as the carcinogenic situation should take into account the following:

1) regularities in spatial changes of examined factors for certain period of time;

2 ) regularities in changes of factor features over the time;

3) delay of impact by factor characteristics on final effect (cancer morbidity).

While studying cancer morbidity being a result of interaction of human population with a combination of

\section{References}

1. MacMahon, B., Pugh, T. F, Ipsen, J. 1965, Application of the epidemiological methods in studies of non infectious diseases. [In Russian, translated from English]. Moscow: Meditsina, 318 p.

2. Chaklin, A. V. 1970, Methods on studying the epidemiology of malignant tumors. Moscow (in Russian).

3. Higginson, C. S. Muir, and N. Munoz. 1992, Human environmental carcinogenic and carcinogenesis modifying factors, one should keep in mind that such an interaction occurs within certain body function systems. In order to model the carcinogenic situation, it is important first of all to proceed from information about specific functions of the body organ affected by cancer and the function system of its internal and external relationships established during their long-term evolution.

Cancer prevention per se is a process to manage the carcinogenic situation. This management should take into account numerous internal and external interactions pertaining to the object which is being managed. The fundamentals for problem solving in such a management process are contained in the very structure of the carcinogenic situation which is a multilevel hierarchically built system. At each level, an appropriate tasks should be accomplished, appropriate methods and means be used.

At the first level of the carcinogenic situation system (population level), the environmental quality management tasks are addressed, the compensation for adverse natural environmental conditions is conducted, the harmful effects of science and technology progress are eliminated in social and other areas.

At the second level of system management (human body), the measures to maintain the general and immune homeostasis should be carried out by implementing a non-specific exposure, balancing a diet especially its mineral and vitamin components, breaking bad habits (smoking and alcohol abuse), optimizing the reproductive behavior.

At the third level (selected body organ), it is necessary to provide for measures to identify the risk group individuals with pre-cancerous condition as well as their treatment and medical case monitoring.

To conclude, the methodology for the system research and management of the carcinogenic situation represents a new step towards cancer prevention problem solution which permits to develop an objective view about existing specific cancer morbidity and to apply targeted preventive measures.

Cancer: Epidemiology and Environmental Causes, by J. Cambridge Monographs on Cancer Research. Cambridge, England: Cambridge University Press, 577 p.

4. Raikhman, Y. G. 2006. «System of the concept of a carcinogenic situation, research and management methodology", Thought, Israel,no. 2, pp. 21-26.

5. Kundiyev, Yu. I., Nagorna, A. M., Varyvonchyk, D. V. 2008, Occupational Cancer. Epidemiology and Prevention, Kyiv: Naukova Dumka, 336 p. 
6. Shabad, L. M. 1967, Pre-cancer in experimental and morphological aspects, Moscow (in Russian).

7. Axel, E. M., Dvoirin, V. V. 1990, «Dynamics of morbidity of malignant neoplasms of the Soviet population, 1985-1989 years", Malignant neoplasms in the USSR, 1985-1989 years, Moscow, pp. 65-94 (in Russian).

8. Belyakov, V. D. 1995, Selected lectures on general epidemiology of infectious and non-infectious diseases, Moscow, 176 p. (in Russian).

9. Raikhman, Y. G. 1985, Methodology of the system research on a carcinogenic situation, Publishing House of Rostov University, Rostov-on-Don. 150 pp. (in Russian).
10. Raikhman, Y. G. 1989. Development of a carcinogenic situation in conditions of scientific and technological revolution, Publishing House of Rostov University, Rostov-an-Don, $176 \mathrm{pp}$.

11. Raikhman, Y. G., Beretar, S. H. 1997, National traditions and cancer, Maikop, Russia, 302 p. (in Russian).

12. Raikhman, Y. G. 1999, Management of a carcinogenic situation and prevention of cancer (a system approach). Elista, Russia (in Russian).

13. Raikhman, Y. G. 2009, Theoretical bases of cancer prevention, Ashdod, Israel (in Russian).

\section{Райхман я. Г.}

\section{ФУНААМЕНТААЬНЫЕ ПОЛОХКЕНИЯ МЕТОАОЛОГИИ ИССАЕАОВАНИЯ ПРИЧИН РАКА}

\section{Шентр профилактики рака, АшАод - Израиль}

Несоответствие методов эпидемиологического исследования рака тем условиям, в которых живут человеческие популяции, часто приводило к ошибочным заключениям о причинах болезни и неэффективности предлагаемых мер его предотвращения. В статье представлен новый методологический подход к исследованию причин рака на основе концепции автора о канцерогенной ситуации как многоуровневой развивающейся системе. Методология системного исследования канцерогенной ситуации создала перспективы установления причин существующих особенностей заболеваемости рака под влиянием многофакторного комплекса условий окружающей среды и образа жизни населения. Исследование канцерогенной ситуации выполнено на основе статических и динамических моделей. Динамические модели - основание для разработки прогноза заболеваемости рака. Методология исследования системы и управление вызывающей рак ситуацией открывают новые перспективы в решении проблемы предотвращения рака.

Ключевые слова: эпидемиология рака, канцерогенная ситуация, методология исследования системы

Поступила: 14.10.2013 2.

Контактное лицо: Райхман Я. Г., доктор медицинских наук, Центр профилактики рака, Ашдод - Израиль raihonko@bezeqint.net, http://www.all-about-cancer-prevention.com/about.html 